\title{
Redes sociais, novos media e SRSs
}

\author{
Pedro Miguel Alves Ribeiro Correia \\ Maria Faia Rafael Moreira
}

\section{Introdução: definição de rede social}

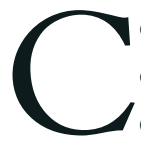

onhecer e analisar o fenômeno dos sites de redes sociais (SRS), tal como os conhecemos atualmente, exige, primeiramente, uma análise da evolução do próprio conceito de rede social, no seu sentido mais lato, bem como do contexto em que surgiu e de como foi explorado do ponto de vista da investigação.

As origens do conceito de rede social remontam ao século XIX, com os esforços de Auguste Comte para desenvolver a sociologia como ciência. Publicadas entre 1839 e 1842, as obras de Comte responsabilizam a sociologia com a tarefa de descortinar as leis da sociedade, devendo focar-se nas inter-relações entre os diferentes elementos que a constituem. Esta definição de Comte terá sido o alicerce fundador da análise de redes sociais, ao assumir uma visão estrutural da sociedade como um sistema de conexões entre os atores sociais (Freeman, 2004).

Já em finais do século XIX destacam-se Ferdinand Tönnies e Émile Durkheim como os principais precursores desta perspetiva. Tönnies distinguiu duas formas de vínculos entre grupos sociais: os vínculos tradicionais ou informais, que interligam indivíduos com crenças e valores em comum; e os vínculos formais, de cariz instrumental, resultantes do contrato social entre o indivíduo e o grupo. Tal como Tönnies, também Durkheim distingue a solidariedade mecânica - que interliga os indivíduos através de regras opressivas - e a solidariedade orgânica, que provocada pela divisão do trabalho na sociedade moderna, surge de inter-relações de cooperação entre indivíduos (Freeman, 2004). 
No início do século XX, os trabalhos de Georg Simmel constituem a mais explícita visão estrutural da sociedade, afirmando que um grupo alargado pode ser considerado como uma sociedade quando as ações de um indivíduo produzem, direta ou indiretamente, efeito sobre outro indivíduo. Posteriormente, Leopold von Wiese (aluno de Simmel) chega mesmo a usar termos como sistema de relações ou rede com linhas que interligam os homens, na sua definição de sociedade (Freeman, 2004).

Em 1934 é publicada a obra Who Shall Survive?, pioneira no registo sistemático e na análise de interações sociais em pequenos grupos. Jacob Moreno, o seu autor, foi considerado por vários investigadores como o pai da sociometria (Hummon e Carley, 1993; Degenne e Forsé, 1994; Wasserman e Faust, 1994), que pode ser definida como um método quantitativo que permite medir relações sociais. Segundo Moreno "Os testes e análises sociométricas permitem revelar estruturas escondidas que dão forma a um grupo social: as alianças, os subgrupos, as crenças secretas, os tabus e as ideologias, são as verdadeiras estrelas da sociometria" (Moreno, 1953).

Outros autores (Mullins e Mullins, 1973; Berkowitz, 1982; Scott, 2000) minimizam a relevância do papel de Moreno na história da sociometria, defendendo que só a partir da década de 1960 com os trabalhos de Harrison White se dá origem, em definitivo, ao início da análise de redes sociais. Ao permitirem a realização de inferências sobre o modo como se formam determinados grupos sociais através da identificação de padrões de interação entre indivíduos, os trabalhos de White e dos seus alunos de Harvard representaram a transformação da visão tradicional da sociedade, em que as estruturas sociais eram consideradas como um resultado dos interesses comuns de um grupo de indivíduos, num novo paradigma, em que a sociedade passou a ser encarada como consequência de padrões relacionais (Breiger, 2005). Segundo White (2008) é um erro associar atributos a estruturas sociais que resultam de padrões relacionais. Assim, afirmar, por exemplo, que existe um conjunto de atributos típicos de líder pode ser um erro, já que um líder só pode existir como tal, devido ao padrão relacional que os restantes indivíduos do seu grupo mantém com este.

Ainda na década de 1960, Stanley Milgram também investigador em Harvard, marcou a história da análise de redes sociais por ter efetuado um conjunto de experiências, The Small World Experiments, que vieram confirmar a noção de que a sociedade humana estaria cada vez mais interligada (Freeman, 2004). Milgram concluiu que, entre o total da população dos Estados Unidos, quaisquer dois indivíduos selecionados aleatoriamente estariam separados em média, por seis relações, também designadas por "nós" da rede (Travers e Milgram, 1969).

Inúmeros estudos inspirados nas experiências de Milgram foram e continuam a ser replicados e aplicados também em contextos de sites de redes sociais, entre os quais se destaca o estudo de Duncan Watts que revela que, no caso de 
uma rede de utilizadores de email, existem pelo menos sete nós entre dois indivíduos selecionados aleatoriamente (Watts, 2004). Tal como esta tese de Milgram, a investigação sobre a temática de redes sociais fundada em problemáticas de âmbito sociológico deu lugar a um universo de investigação interdisciplinar, pelo que atualmente o termo rede social tem aplicabilidade nas mais diversas áreas do conhecimento: na matemática, na economia, no marketing, na informática e, sobretudo com o desenvolvimento dos sites de redes sociais, tornou-se um tema incontornável nas ciências da comunicação.

Este artigo parte da definição histórica de rede social, no seu sentido mais lato (off-line), e propõe uma reflexão sobre o conceito de site de rede social, explorando-o enquanto caso particular dos novos media ao serviço das redes sociais.

\section{Redes sociais e novos media}

Também incontornável nas ciências da comunicação é o contributo de Manuel Castells Oliván, ao consolidar nos seus estudos o termo "sociedade em rede". Castells sustenta que termos como rede ou mesmo rede social desassociados do contexto on-line, se tornaram obsoletos face à era digital em que vivemos. Segundo o autor, "(...) numa sociedade em rede, as atividades e estruturas sociais estão organizadas em torno de redes de informação eletronicamente geridas" (Castells, 2001), pelo que o termo digital é crucial na definição da sociedade contemporânea. Uma das definições atuais de site de rede social que abarca as principais considerações teóricas incorporadas no conceito de rede social e transferidas para o ambiente digital é sugerida por McQuail (2010): "SRS são sites concebidos para permitir e encorajar os utilizadores a criarem redes de contactos e a partilharem mensagens e conteúdos audiovisuais, que frequentemente são direcionados a um público abrangente". Exemplos emblemáticos de sites de redes sociais são o Facebook, o MySpace e o YouTube, que atingiram um elevado valor comercial, especialmente pelo seu potencial de comunicação viral e pelas sofisticadas possibilidades que oferecem, às marcas anunciantes, de segmentação da publicidade para um dado público-alvo.

Apesar de atualmente estarem intimamente relacionados, enquanto o termo rede social tem mais de um século de história, já a expressão novos media tem apenas algumas décadas de existência, tendo começado por ser usada na década de 1960. Desde então, os novos media utilizam um conjunto crescente de tecnologias da comunicação, cada vez mais diversificado. Lievrouw e Livingstone (2006) definem novos media como uma "combinação de tecnologias da informação e da comunicação e os seus contextos sociais, encadeando 1) artefactos e dispositivos tecnológicos, 2) atividades, práticas e usos dos mesmos e 3 ) estruturas sociais formadas em torno dessas práticas”. 
Uma vez que esta definição pode ser facilmente aplicada aos media tradicionais, apenas salientando que os artefatos, usos e estruturas são distintos dos considerados no contexto on-line, não é possível distanciar esta definição das características essenciais que os distinguem e que consistem em: a) interconectividade, b) interatividade, c) acessibilidade a utilizadores individuais (sejam receptores ou emissores), d) multiplicidade de usos, e) propensão para constantes desenvolvimentos/melhorias e f) ubiquidade. Ainda sobre estas características, há necessariamente que sublinhar as mudanças geradas pelos novos media no papel das audiências. Face aos media tradicionais, os novos media possibilitam à audiência não apenas maior autonomia, mas também maior democracia no que respeita às fontes de informação. Por este motivo, no contexto on-line, um membro da audiência já não é realmente um elemento constituinte das massas, mas sim um membro de uma rede auto selecionada, um público particular ou, simplesmente, um indivíduo (McQuail, 2010). E, efetivamente, tal como afirma Leclerc:

Se a internet levanta tantas paixões e tanta admiração, tantas esperanças, mas também tantos medos e algumas vezes escândalos, tal acontece porque instaurou a sociedade da ubiquidade no plano das mensagens entre particulares, o que põe fim à dissimetria entre os emissores e os recetores de mensagens (Leclerc, 2000).

O equilíbrio da atividade de uma audiência passou da receção para uma pesquisa e uma interação mais pessoais, resultando na premência de complementar o conceito de audiência com o termo utilizador que se lhe sobrepõe, apesar das suas diversas conotações (McQuail, 2010).

\section{Sites de redes sociais (SRS)}

Desde a sua gênese, sites de redes sociais como o Facebook, o MySpace, o Hi5 ou o LinkedIn, atraíram milhões de utilizadores, que passaram a incluir a utilização dos mesmos na sua rotina diária. Atualmente existem centenas de sites de redes sociais, criados para perfis de utilizadores muito segmentados ou com objetivos muito especializados, do qual é exemplo, o LinkedIn, o maior site de rede social de perfis de profissionais. Apesar de terem características tecnológicas globalmente similares, as culturas que emergem em torno dos diferentes sites de redes sociais são muito diversificadas. E se uma parcela significativa dos sites de redes sociais apoia a manutenção de redes sociais já existentes, outra parte significativa permite que desconhecidos se conectem on-line, com base nos seus interesses comuns, preferências políticas ou mesmo atividades em comum. Enquanto alguns sites de redes sociais se dirigem a audiências diversificadas, outras atraem utilizadores com base num idioma, 
ou numa identidade racial, sexual, religiosa ou nacionalidade comuns. Os sites de redes sociais também variam na extensão em que incorporam novas ferramentas de informação e de comunicação, tal como a conectividade móvel, o blogging, e a partilha de fotografias e/ou vídeos (Boyd e Ellison, 2007).

\section{Definição e principais características dos SRS}

Segundo a acepção de Boyd e Ellison (2007), os sites de redes sociais podem definir-se como sistemas que prestam serviços on-line e que permitem aos indivíduos a realização de um conjunto particular de atividades, concretamente: 1. a criação de um perfil público ou semi-público, num sistema limitado; 2 a articulação e exploração de uma lista de outros utilizadores com quem partilham alguma relação; 3 . a exploração das listas de relações de outros utilizadores do sistema. Não obstante esta generalização, é de notar que a natureza e nomenclatura destas relações pode variar de site rede social para site de rede social.

Mas não é o fato de permitirem que utilizadores desconhecidos se interliguem, que torna os sites de redes sociais únicos. O que dota os sites de redes sociais de um caráter único, que os distingue das demais tipologias de sites, é a possibilidade de articulação das relações que os utilizadores estabelecem e mantêm, e a possibilidade de publicarem conteúdos no âmbito da sua rede social. Embora esta caraterística possa resultar em conexões entre indivíduos que de outro modo não ocorreriam, esse não parece ser o objetivo principal dos sites de redes sociais, uma vez que grande parte das conexões acabam por acontecer entre laços latentes, ou seja, entre utilizadores que partilham algum tipo de relação no contexto off-line (Haythornthwaite, 2005). Efetivamente, em grande parte dos sites de redes sociais de maior dimensão (em termos de utilizadores $)^{1}$, os participantes não estão necessariamente em rede com o objetivo de fazer novos conhecimentos. Assim, o objetivo primeiro da presença num site de rede social é o de comunicar com pessoas que já fazem parte da rede social do utilizador (Haythornthwaite, 2005).

Apesar da vasta diversidade de funcionalidades que disponibilizam, é possível afirmar que a estrutura central de um site de rede social consiste num conjunto de perfis de utilizadores, perfis esses que apresentam uma lista de amigos que, por sua vez, também são utilizadores do site em questão. Os perfis são páginas únicas, onde o utilizador se apresenta. Após ser membro de um site de rede social, o utilizador preenche um formulário com um conjunto de questões, e é com base nas respostas a essas questões que é gerado o perfil que tipicamente inclui: a idade, a localização geográfica, os interesses, as preferências e uma seção designada about me (sobre mim), com informações mais detalhadas acerca da educação, profissão, etc. A maioria dos sites de redes sociais também encoraja os utilizadores a usarem pelo menos uma fotografia que deverá constar no perfil e complementá-lo. Alguns sites 
de redes sociais permitem complementar o perfil com conteúdos multimídia ou modificar o aspeto gráfico e a estética do mesmo. A título de exemplo, o Facebook ${ }^{2}$ permite ainda que os utilizadores adicionem módulos (denominadas aplicações ou apps) que servem de completamento e também permitem a otimização do perfil a vários níveis (Boyd e Ellison, 2007).

A visibilidade do perfil varia entre os sites de redes sociais e de acordo com o grau de discrição estabelecido pelo utilizador. Por predefinição, perfis de sites como o Friendster ou o Tribe.net são monitorizados por motores de busca, tornando-os visíveis publicamente, independentemente de a procura ser realizada por um membro dessas redes sociais ou não. Já sites como o LinkedIn controlam o que está visível para outros utilizadores se estes tiverem uma conta premium, que consiste num serviço pago. Sites como o MySpace permitem que os utilizadores escolham o nível de visibilidade do seu perfil, que pode ser público ou apenas visível para amigos. Já o Facebook adotou uma abordagem distinta, já que, por defeito, os utilizadores que fazem parte da mesma rede de amigos podem visualizar o perfil uns dos outros, a menos que o utilizador tenha optado especificamente por negar a visualização do seu perfil aos membros dessa rede. Estas variações estruturais no que concerne à visibilidade e ao acesso aos perfis são as características que traçam as grandes distinções entre os vários sites de redes sociais (Boyd e Ellison, 2007).

Uma vez membros de um site de rede social, os utilizadores são motivados a identificar outros utilizadores no sistema, com quem mantêm uma relação. A designação para estas relações depende do site em questão, mas as expressões mais populares são amigos, contatos e fãs. Normalmente, os sites de redes sociais requerem uma confirmação bidirecional para que possa ser estabelecida uma conexão entre dois utilizadores, mas alguns não o exigem. Por sua vez, as relações unidirecionais são caracterizadas por termos comofãs ou seguidores, mas muitos sites de redes sociais também as denominam de amigos. Assim, o termo amigos, neste contexto, pode ser enganador, pois a relação referida pode não corresponder necessariamente a uma amizade, no sentido comum do termo, e as razões que levam as pessoas a assumir este tipo de relações são as mais diversas (Boyd, 2006).

A divulgação das relações é um componente crucial dos sites de redes sociais e em torno da qual se desenvolveram a maioria destes sites. A lista de amigos contém ligações ao perfil de cada amigo do utilizador, permitindo que outros utilizadores explorem a sua rede de contatos. Essa lista está geralmente visível a quem tenha permissão para ver o perfil do utilizador, embora haja exceções. No caso do MySpace, por exemplo, alguns utilizadores conseguiram violar essa regra de forma a que o seu perfil não mostrasse a lista de amigos. Outro exemplo é do LinkedIn, que permite ocultar a rede de contatos no perfil. Regra geral, os sites de redes sociais também oferecem um sistema para os utilizadores poderem deixar mensagens nos perfis dos seus contatos. Esta funcionalidade envolve a partilha de comentários, apesar de estas 
mensagens assumirem designações muito distintas consoante o site em questão. Uma funcionalidade muito próxima ao serviço de email oferecida por grande parte dos sites de redes sociais, é o envio de mensagens privadas entre pares de utilizadores (Boyd e Ellison, 2007).

Mas nem todas estas redes sociais digitais se desenvolveram em torno dessas funcionalidades. O QQ, na China, teve início como serviço de mensagens instantâneas; o LunarStorm começou como um site de uma comunidade on-line; o Cyworld como uma ferramenta para fóruns de discussão; e o Skyrock (antigo Skyblog), em França, como um serviço de blogging, tendo todos posteriormente implementado funcionalidades típicas de sites de redes sociais. O Classmates.com, uma rede de escolas lançada em 1995, começou a articulação de listas de amigos muito depois de os sites de redes sociais se terem tornado populares. Os sites AsianAvenue, MiGente e BlackPlanet foram os primeiros sites de comunidades étnicas a alcançarem popularidade com funcionalidades limitadas de amizade, antes de se relançarem em 2006 com características e funcionalidades típicas de sites de redes sociais (Boyd e Ellison, 2007).

Além dos perfis, amigos, comentários e mensagens privadas, os sites de redes sociais distinguem-se entre si pelas funcionalidades de partilha que oferecem e pela base de utilizadores que geraram e mantêm. Alguns destes sites oferecem possibilidades de partilha de fotografias e vídeos, enquanto outros têm incorporada tecnologia de escrita em blogs e de mensagens instantâneas. Existem até sites de redes sociais específicos para comunicações móveis (o Dodgeball, por exemplo), embora a tendência atual seja a de sites de redes sociais desenhadas para a web também suportarem interações, ainda que limitadas, via móvel (como o caso Facebook, do MySpace e do Cyworld). Esta mobilidade acrescida ajuda a justificar a crescente facilidade de utilização das redes sociais digitais sem restrições geográficas. Porém, muitos sites de redes sociais têm, como segmento-alvo, utilizadores de uma determinada região geográfica ou que falam determinado idioma, podendo acontecer que a constituição da base de utilizadores acabe por não coincidir com o segmento para o qual o site foi inicialmente criado. O Orkut, por exemplo, foi lançado nos EUA somente na versão inglesa, mas os brasileiros acabaram por constituir o grupo dominante na sua base de utilizadores (Kopytoff, 2004).

Como foi anteriormente mencionado neste artigo, alguns sites de redes sociais são criados com base em determinadas categorias identitárias específicas, como sejam a etnia, a religião, a orientação sexual ou a política. Existem mesmo sites de redes sociais para cães (Dogster) e gatos (Catster), cujos perfis são geridos pelos seus donos. Apesar de, na sua maioria, serem concebidos para uma fácil acessibilidade, muitos sites de redes sociais acabam por atrair populações inicialmente homogêneas. É portanto comum, encontrar grupos que usam redes sociais digitais com o objetivo de auto-segregação pela nacionalidade, idade, nível de formação 
acadêmica, ou outros aspectos sociodemográficos que frequentemente segmentam a sociedade, ainda que esse não tenha sido o propósito da sua criação (Hargittai, 2007). Não pode, portanto, deixar de se conjecturar que a forma como a natureza humana subjacente às interações nas redes sociais digitais, a mesma natureza que terá governado o comportamento das sociedades ao longo dos milênios, com o que pode ser entendido como uma tendência para a criação de discriminações e estereótipos, encontrou o seu caminho por entre o despontar das novas tecnologias de informação e comunicação.

\section{Considerações finais}

Com começos improváveis e cerca de uma década de existência, os sites de redes sociais constituem um novo, fértil e promissor campo de pesquisa para as ciências sociais, em geral, e para as ciências da comunicação, em particular.

Fazendo a síntese entre conceitos clássicos, como o de rede social, e entre as novas tecnologias, associadas aos novos media, os sites de redes sociais dão continuidade às características e comportamentos dos seres humanos, enquanto animais sociais, e projetam essas características e comportamentos para novos patamares de imediatismo e ubiquidade que cada vez mais tocam todos os aspetos da vida contemporânea. Cabe à ciência e à comunidade científica a tarefa e a responsabilidade de abordar e aprofundar o conhecimento sobre estes temas, e simultaneamente facultar à sociedade esse conhecimento, não enviesado por ideologias ou dogmas injustificados.

A reflexão apresentada neste artigo procura não só clarificar os conceitos de rede social, novos media e site de rede social mas também sistematizar as inter-relações existentes entre estes constructos, temáticas incontornáveis da vivência em sociedade no início deste novo milênio.

Pedro Miguel Alves Ribeiro Correia Professor e investigador integrado da Universidade de Lisboa (ULisboa) pcorreia@iscsp.ulisboa.pt.

Maria Faia Rafael Moreira Doutoranda na Universidade de Lisboa (ULisboa) maria.faia@gmail.com

Recebido em junho de 2015.

Aceito em dezembro de 2015. 


\section{Notas}

1. Informação adicional sobre sites de redes sociais de larga escala pode ser encontrada em Correia e Moreira (2015).

2. Informação adicional sobre o Facebook e a sua primeira década de existência pode ser encontrada em Correia e Moreira (2014).

\section{Referências}

BERKOWITZ, Stephan. An Introduction to Structural Analysis: The Network Approach to Social Research. Toronto: Butterworth and Co., 1982.

BOYD, Danah e ELLISON, Nicole. Social Network Sites: Definition, History, and Scholarship. Journal of Computer-Mediated Communication, 13 (1): 210-230, 2007.

BREIGER, Ronald. Culture and Classification in Markets: An Introduction. Poetics, 33 (34): 157-162, 2005.

CORREIA, Pedro e MOREIRA, Maria. Novas formas de comunicação: história do Facebook - Uma história necessariamente breve. ALCEU: Revista de Comunicação, Cultura e Política, 14 (28): 168-187, 2014.

Três grandes marcos da primeira década de história dos sites de redes sociais de larga escala: Friendster, MySpace, Facebook e a sua atomização em sites de redes sociais de nicho. ALCEU: Revista de Comunicaşão, Cultura e Política, 15 (30): 104-116, 2015.

DEGENNE, Alain e FORSÉ, Michel. Introducing Social Networks. SAGE Publications, 1994. FREEMAN, Linton. The Development of Social Network Analysis. Vancouver: Empirical Press, 2004.

HARGITTAI, Eszter. Whose Space? Differences Among Users and Non-Users of Social Network Sites. Journal of Computer-Mediated Communication, 13 (1): 276-297, 2007.

HAYTHORNTHWAITE, Caroline. Social Networks and Internet Connectivity Effects. Information, Communication \& Society, 8 (2): 125-147, 2005.

HUMMON, Norman e CARLEY, Kathleen. Social Networks as Normal Science. Social Networks, 15 (1): 71-106, 1993.

LECLERC, Gérard. A sociedade de comunicação: uma abordagem sociológica e crítica. Lisboa: Instituto Piaget, 2000.

LIEVROUW, Leah e LIVINGSTONE, Sonia. Handbook of New Media: Social Shaping and Social Consequences of ICTs. London, UK: SAGE Publications, 2006.

McQUAIL, Denis. Mass Communication Theory. 6 ed. Londres: Sage Publications, 2010.

MORENO, Jacob. Who Shall Survive?: Foundations of Sociometry, Group Psychotherapy and Sociodrama, $2^{\mathrm{a}}$ edição. Beacon House, 1953.

MULLINS, Nicholas e MULLINS, Carolyn. Theories and Theory Groups in Contemporary American Sociology. New York: Harper and Row, 1973.

SCOTT, John. Social Network Analysis: A Handbook. 2a ed. Newbury Park, CA: Sage, 2000. TRAVERS, Jeffrey e MILGRAM, Stanley. An Experimental Study of the Small World Problem. Sociometry, 32 (4): 425-443, 1969.

WASSERMAN, Stanley e FAUST, Katherine. Social Network Analysis: Methods and Aplications. Cambridge University Press, 1994. 
WATTS, Duncan. Six Degrees: The Science of a Connected Age. New York: W. W. Norton \& Company, 2004.

WHITE, Harrison. Identity and Control: How Social Formations Emerge. Princeton University Press, 2008.

\section{Endereços eletrônicos}

BOYD, Danah. Friends, Friendsters, and MySpace Top 8: Writing Community into Being on Social Network Sites. First Monday, v. 11, n. 12, 4 de dezembro de 2006. Disponível em: < http://firstmonday.org/ojs/index.php/fm/article/view/1418/1336>. Acesso em: 30 de março de 2015.

CASTELLS, Manuel. Identity and Change in the Network Society: Conversation with Manuel Castells (KREISLER, Harry. (ent.). Conversations with History; Institute of International Studies, UC Berkeley, 9 de maio de 2001. Disponível em: < http://globetrotter.berkeley.edu/ people/Castells/castells-con4.html> . Acesso em: 31 de fevereiro de 2015.

KOPYTOFF, Verne. Google's Orkut Puzzles Experts / Internet Watchers Ponder Reason for Social Network Site. San Francisco Chronicle, 29 de novembro de 2004. Disponível em: < http:// www.sfgate.com/business/article/Google-s-Orkut-puzzles-experts-Internet-2633049.php>. Acesso em: 30 de janeiro de 2015.

\section{Resumo}

$\mathrm{Na}$ atualidade, os sites de redes sociais (SRS) são alvo de intenso escrutínio por parte de inúmeros acadêmicos e investigadores, atraídos pelo seu potencial, tanto ao nível das funcionalidades que disponibilizam, como ao nível do extraordinário número de utilizadores que conseguiram angariar num período de atividade que pode ser considerado relativamente reduzido. Este artigo parte da definição histórica de rede social, no seu sentido mais lato (offline), e propõe uma reflexão sobre o conceito de site de rede social, explorando-o enquanto caso particular dos novos media ao serviço das redes sociais.

\section{Palavras-chave}

Redes sociais. Novos media. Sites de redes sociais (SRS). Definição. Principais características.

\section{Abstract}

Social Networks, New Media and SNSs

At the present, social networking sites (SNS) are subject to intense scrutiny from numerous scholars and researchers, attracted by their potential, both in terms of functionalities provided, and in terms of the extraordinary number of users gathered in what can be considered a relatively small period of activity. This article begins with the historical definition of social network, in the broad sense (offline), and proposes a reflection on the concept of social network site, exploring it as a particular case of new media at the service of social networks.

\section{Keywords}

Social networks. New media. Social networking sites (SNS). Definition. Main characteristics. 